\title{
EXPRESSION OF TGFB-3, PAX9, RYK, MATRIX METALLOPROTEINASES AND THEIR TISSUE INHIBITOR IN HUMAN CLEFT-AFFECTED TISSUE
}

\author{
Benita Krivicka ${ }^{1}$, Mara Pilmane ${ }^{1}$, Ilze Akota ${ }^{2}$ \\ ${ }^{1}$ Department of Morphology, Institute of Anatomy and Anthropology, \\ Riga Stradiňs University, Riga, Latvia \\ ${ }^{2}$ Department of Oral and Maxillofacial Surgery, Institute of Stomatology, \\ Riga Stradiņš University, Riga, Latvia
}

\begin{abstract}
Formation of mammalian lip and palate involves multiple developmental steps that finally lead to the fusion of the two bilateral palatal shelves along the facial midline. Recent studies confirm that on the basis successful orofacial formation is coordinated interactions of several factors including genes, growth factors, enzymes and their natural inhibitors. The aim of our study was to investigate cleft disordered tissue in children with cleft lip and palate for detection of local expression of key regulators of palatogenesis.

The study involved 10 patients with unilateral cleft lip and palate at the age of three months to four years and eight months. Tissue samples were collected during the surgical procedure from the borders of the cleft region. Material was proceed for detection of PAX9, RYK, TGF $\beta$-3, MMP-8, MMP-9 and TIMP-2 with biotin-streptavidin immunohistochemistry. Distribution of immunoreactive structures was detected semiquantitatively.

Expression of PAX9 and RYK was more pronounced in cleft lip and palate disordered epithelium. The relative number of PAX9 positive epitheliocytes was very variable, while RYK mainly stained few cells localized into middle layers. Expression of TGF $\beta-3$ was detected in the tissue of all patients. We saw numerous positive epitheliocytes in eight cases, but underlying connective tissue mainly demonstrated few or moderate number immunoreactive cells. Expression of MMP-8 was found only in epithelium of eight patients and it was slight, while MMP-9 and TIMP-2 marked variable number of positive epithelial and connective tissue cells.
\end{abstract}


Conclusions. Expression of Pax-9 is more characteristic for cleft lip and palate affected tissue and probably facilitates tissue reconstruction due to its mitogenic effect. Rich expression of TGF $\beta-3$ in cleft lip and palate disordered tissue may play a role in successful tissue remodelling and scar-free healing. Cleft lip and palate disordered tissue are characterizied by more pronounced expression of MMP-9, it slightly predominate expression of TIMP-2, giving evidence to the involvement of mentioned factors in the postnatal tissue remodeling.

Keywords: cleft lip and palate, PAX9, RYK, MMP, TIMP-2, TGF $\beta-3$

\section{INTRODUCTION}

Clefts of the lip and palate are among the most common birth defects in humans and occur at the approximate rate of 1 in 700 live births with wide variability related to geographic origin and socioeconomic status [15, 21]. Cleft palate is caused by the failed closure of bilateral palatal shelves in the midline [21].

The development of human secondary palate involves a complex sequence of critical events, including the growth, elevation, medial elongation and midline fusion of palatal shelves $[5,21]$. Consequently, the bilateral shelves establish contact at midline at the tip epithelium named the medial edge epithelium (MEE), forming the medial epithelial seam (MES) [11]. Complete fusion of the secondary palate requires disappearance of the MEE, as well as the breakdown of their basement membrane [1]. Exactly, the cell fate of MEE is controversial more then 20 years, and among possible mechanisms for the disappearance are apoptosis, epithelial/mesenchymal transformation and /or cell migration [11]. Studies show, that all mentioned processes are caused and regulated by different genes, matrix metalloproteinases (MMPs) and tissue inhibitors of metalloproteinases (TIMPs).

The PAX gene family consists of 9 members, that based on the presence or absence of structural motifs, are divided into 4 subgroups. The functions and role of PAX genes in embryonic development have been elucidated by analysis of naturally occuring mouse mutants and human syndroms. A common feature of all PAX mutants is reduction in size and malformation or loss of specific organs. Several PAX genes, among them PAX9, are expressed in the developing facial processes [4].

PAX9 is a key regulator in mesenchyme during the development of a wide range of organ primordia, including the palatal shelf. Researchers confirm that 
there is a direct correlation between Pax-9 expression and palatal fusion [8]. Moreover, Heiko and his coworkers showed, that PAX9 regulates the normal shape of the palatal shelves prior to shelf elevation. They demonstrated that the shelves of PAX9 mutant embryos revealed an abnormally broadened shape and lacked characteristic indentations at their ventrolateral sides [9].

$\mathrm{RYK}$ is an atypical orphan receptor tyrosine kinase that lacks detectable kinase activity. The exact function of RYK is unknown, and its ligand has not been identified. A mouse model, where RYK was homozygously deleted by homologous recombination, revealed an unusual, completely penetrant phenotype. The mice were small, compared with wild type, and died within a week because of cleft palate [24]. Studies on humans also approve that mutations of RYK is genetic factor for cleft lip and palate [25].

Transforming growth factor beta -3 (TGF $\beta-3$ ) orchestrates fusion of the palatal seam [14]. It is expressed abundantly by the palatal MEE and is critical for the adhesion and disappearance of the MEE during normal palatal shelf fusion [23]. In the TGF- $\beta 3$ null-mutant mice the palatal shelves fail to adhere properly, the basement membrane is not degraded and the MEE do no disappear from the midline seem [17].

Matrix metalloproteinases (MMPs) are a family of zincdependent proteases responsible for tissue remodeling due to their role in extracellular matrix remodeling, degrading molecules from the extracellular matrix and basement membranes, and in promoting cell migration and proliferation. Together with their tissue inhibitors (TIMPs), MMPs have key roles not only during embryogenesis but also in homeostasis of adult tissues $[12,16]$. Moreover, TGF $\beta-3$ induces expression of MMPs and following proteolytic degradation of extracellular matrix (ECM) is a necessary step for palatal fusion [1].

\section{MATERIAL AND METHODS}

The research is based on the material of cleft lip and palate patients, which was gathered within a period of time from 2003 to 2006 at the Cleft Lip and Palate Centre of the Institute of Stomatology of the Riga Stradins University. Permission of the Ethics Committee: decision of the RSU Ethics Committee dated $22^{\text {nd }}$ May 2003.

The research involved 10 patients with unilateral cleft lip and palate at the age from three months to four years and eight months. Tissue samples were collected during the surgical procedure from the borders of the cleft region. 
Tissue were fixed for a day in mixture of $2 \%$ formaldehide and $0,2 \%$ picric acid in $0,1 \mathrm{M}$ phosfate buffer (ph 7,2). After samples were rinsed in thyroide buffer, containing $10 \%$ sacharose for 12 hours, then embedded into paraffin and cut in 6-7 $\mu \mathrm{m}$ thin sections. Sections were proceeded for detection of PAX9 gene (PAX9, orb120466, work dilution 1:50, Biorbyt Limited, UK), RYK gene (RYK, orb38371, work dilution 1:100, Biorbyt Limited, UK), transforming growth factor beta 3 (TGF $\beta-3$, sc-82, work dilution 1:100, Santa Cruz Biotechnology, Inc., USA), matrix metalloproteinase 8 (MMP-8, sc-80206, work dilution: 1:50, Santa Cruz Biotechnology, Inc., USA), matrix metalloproteinase 9 (MMP-9, sc-10737, work dilution: 1:250, Santa Cruz Biotechnology, Inc., USA), tissue inhibitor of matrix metalloproteinases 2 (TIMP-2, sc-21735, work dilution 1:50, Santa Cruz Biotechnology, Inc., USA) by use of Hsu et al. (1981) biotin - streptavidin immunohistochemical method. Routine histological staining with haemotoxylin and eosin was developed for each case to get review picture of the slide. Distribution of immunoreactive structures were detected semiquantitatively [22]. The quantity of structures was analyzed in five visual fields of one section. Scale was as following: " 0 " - no positive structures found in visual field, " $0 /+$ " - occasional positive structures seen in visual field, “+” few immunoreactive structures seen in visual field, “++" - moderate number of immunoreactive structures seen in visual field, " +++ " - numerous immunoreactive structures seen in visual field, and " ++++ " - abundance of immunoreactive structures seen in visual field.

Results were illustrated using Leica DC 300F camera and the image processing and analysis software Image-Pro Plus Version 6.0.

\section{RESULTS}

Expression of PAX9 was observed in the tissue of all patients and it was more prominent exactly in the epithelium. The relative number of positive epitheliocytes was very variable (Table 1). We saw few immunoreactive cells in two cases, but moderate number - in five cases. Mentioned cells mainly localized in the middle layers of stratified squamous epithelium and frequently were vacuolized. Numerous positive cells we found in three cases, but only in one tissue sample they were localized into all layers of epithelium (Figure 1). Expression of PAX9 in cleft lip and palate affected connective tissue was less pronounced. Mainly we saw few positive cells of connective tissue and/or cells of the walls of blood vessels. We didn't find any positive structure in one case, and observed richly stained cells of sebaceous gland in the tissue of one child. 
Table 1. Semiquantitative distribution of immunoreactive structures in the patients with unilateral cleft lip and palate

\begin{tabular}{lcccccc}
\hline Factors & PAX9 & RYK & TGF $\beta-3$ & MMP-8 & MMP-9 & TIMP-2 \\
\hline $\begin{array}{l}\text { Common } \\
\text { evaluation }\end{array}$ & $+-\underline{+-+++}$ & $0-0 /+- \pm-++$ & +-++-+++ & $\begin{array}{c}0-++ \\
\text { variable }\end{array}$ & $\begin{array}{c}0-++/+++ \\
\text { variable }\end{array}$ & $\begin{array}{c}0-++/+++ \\
\text { variable }\end{array}$ \\
\hline
\end{tabular}

0 - no positive structure seen in the visual field; $0 /+$ rare positive structures seen in the visual field; + few positive structures seen in the visual field; $+/++$ few to moderate number of positive structures seen in the visual field; ++ moderate number of positive structures seen in the visual field; $++/+++$ moderate to numerous positive structures seen in the visual field; +++ numerous positive structures seen in the visual field

_ - the most frequently observed quantity of positive structures

variable - very variable number of positive structures

RYK-containing epithelial cells were seen in the tissue of eight patients and their relative number was in the range from occasional to moderate. Mainly we found few positive epitheliocytes localized into middle layers. Expression of RYK in cleft lip and palate disordered connective tissue again was less pronounced. Mainly we found occasional positive fibroblasts and macrophages as well as vascular endothelial and smooth muscle cells. One tissue sample showed richly stained cells in the walls of blood vessels (Figure 2) and moderate number positive cells of sebaceous gland. We didn't observe any positive structures of connective tissue into three cases.

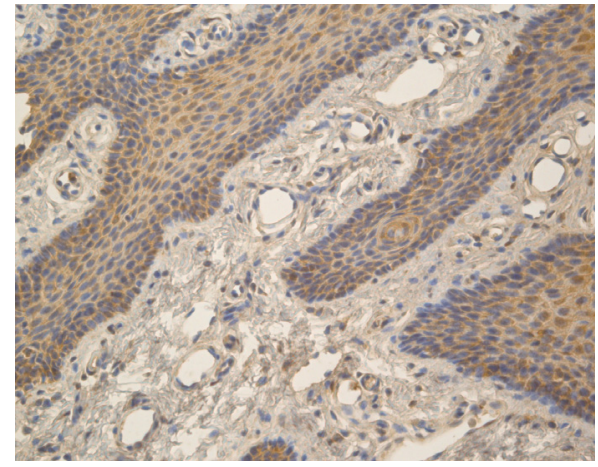

Figure 1. Numerous PAX9 positive epithelial cells. Pax9 IMH, X 250.

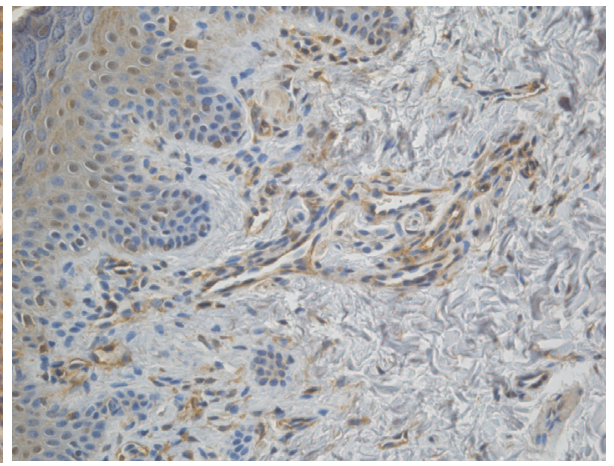

Figure 2. Numerous RYK immunoreactive cells in the walls of blood vesels and regionally localized positive epithelial cells. Ryk IMH, X 250.

Expression of TGF $\beta-3$ was detected in the tissue of all patients. The relative number of positive epitheliocytes was numerous $(+++)$ in eight cases. Interestingly, that positive basal cells we observed in the epithelium of five children 
(Figure 3). Few and moderate number of TGF $\beta-3$ containing epitheliocytes we found each in one case. Connective tissue demonstrated very variable number of TGF $\beta$-3 positive structures. Mainly we observed few or moderate number immunoreactive cells in the connective tissue and in the walls of blood vessels. One tissue sample demonstrated richly stained vascular endothelial and smooth muscle cells (Figure 4).

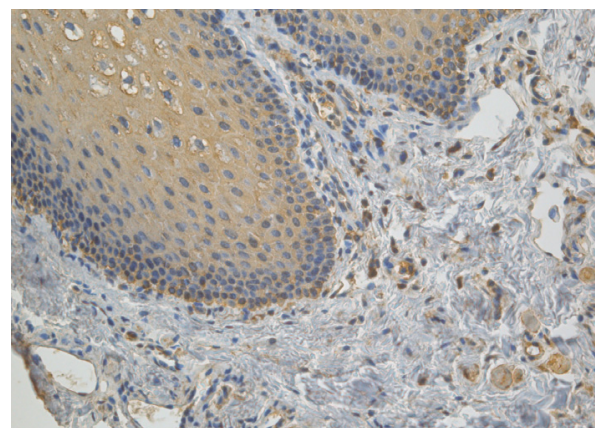

Figure 3. Expression of TGF $\beta-3$ in basal epithelial cells. TGF $\beta-3 \mathrm{IMH}, \mathrm{X} 250$.

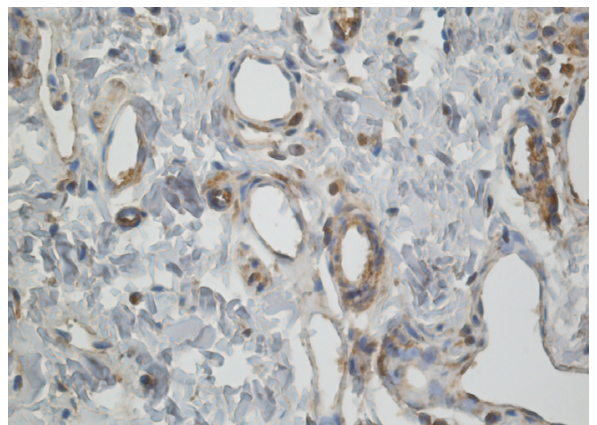

Figure 4. Numerous TGF $\beta$-3 positive vascular endothelial and smooth muscle cells. TGF $\beta-3 \mathrm{IMH}, \mathrm{X} 400$.

Expression of MMP-8 was found in cleft lip and palate affected epithelium of eight patients. We observed few positive cells in three cases and moderate number - also in three cases. Mentioned epitheliocytes mainly were localized in the middle layers of stratified squamous epithelium and frequently were vacuolized (Figure 5). Tissue of one child demonstrated positive reaction of basal cells as well as cells of sebaceous gland. We didn't find any MMP-8 positive structure in the underlying connective tissue.

MMP-9 positive epithelial cells were seen in the tissue of nine patients. Moderate to numerous number of immunoreactive cells was observed in two cases, moderate - in two cases, few - in four cases. Mainly positive reaction demonstrated cells in the middle layers of epithelium, but in three cases it was seen in basal cells. MMP-9 marked occasional epitheliocytes in the tissue material of one child. MMP-9 positive structures in connective tissue were found in the range from absence to numerous in the visual field. We observed numerous fibroblasts, macrophages and lymphocytes in the tissue material of one patient, moderate number of connective tissue cells as well as endotheliocytes and vascular smooth muscle cells - in four cases (Figure 6). Two cleft disordered connective tissue demonstrated few positive cells in subepithelium, but another two - occasional positive cells. 


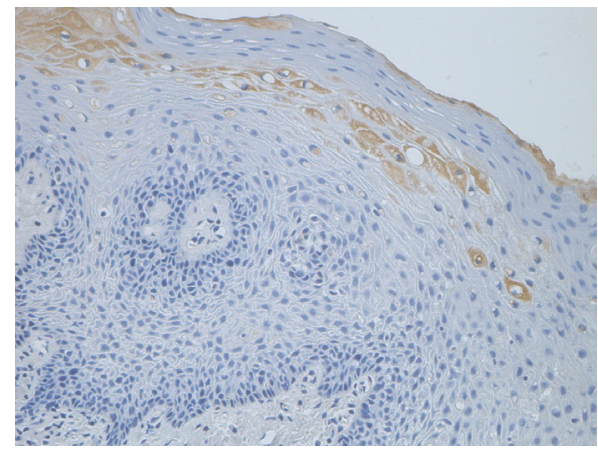

Figure 5. Regionally located MMP-8 positive epithelial cells. MMP-8 IMH, X 200.

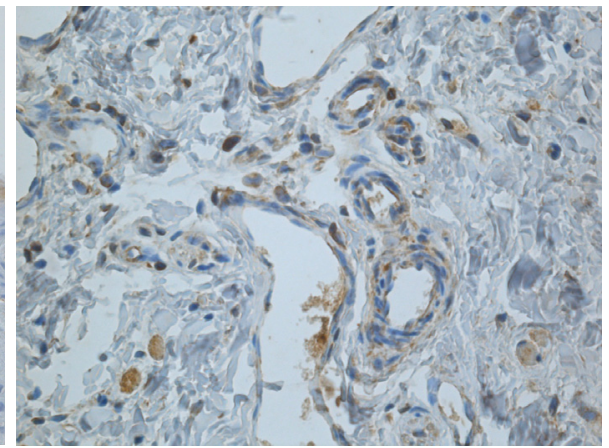

Figure 6. Expression of MMP-9 in connective tissue and vascular endothelial cells. MMP-9 IMH, X 400.

Expression of TIMP-2 was observed in the cleft lip and palate affected epithelium of nine patients. Three tissue samples demonstrated occasional positive epithelial cells, two - few, but one - few to moderate. In all these cases immunoreactivity mainly was seen in the regionally localized and vacuolized cells of middle layers of stratified squamous epithelium. We observed moderate number of TIMP-2 containing epithelial cells in the tissue of two children and moderate to numerous - in one tissue sample. We detected also richly stained cells of sebaceous glands in the tissue of two patients. Expression of TIMP-2 in underlying connective tissue was less pronounced. We saw occasional positive cells of connective tissue in one case and numerous fibroblasts, macrophages and plasma cells also in one case. Four tissue samples demonstrated immunoreactive vascular smooth muscle cells, and relative amount of them varied between occasional to moderate.

\section{DISCUSSION}

Genetic expression is clearly predominant during embrional craniofacial morphogenesis. It is estimated that above two third of human genes play a role in craniofacial development [4]. Moreover, there are data about 40 candidate genes association with cleft lip and palate patients from Baltic region - Estonia, Latvia and Lithuania [18]. The genes are responsible for normal development and encode many different products, including signaling molecules and its receptors, component of extracellular matrix and enzymes [4].

Several families of transcription factors are expressed in the ectomesenchyme, including PAX. PAX9 expression is restricted to prospective tooth mesenchyme at the bud stage, marking the sites of future tooth formation. 
PAX9 also is expressed in the developing facial processes [2, 4]. It is emphasized that mentioned gene is necessary for the capability of the shelves to elevate and to form normal shape [9]. Further, Hilliard with coworkers specify that the expression of PAX9 restricted to the posterior region during palate development and disruption of this gene in mice results in cleft palate [10,13]. Our results showed that expression of PAX9 in tissue taken from cleft lip and palate region is more pronounced exactly in epithelium, but not in the tissue of ectomesenchymal origin. Since PAX9 is a key regulator in mesenchyme during the development and it increases mesenchymal cell proliferation [8], we suppose that thus epithelial tissue demonstrate compensatory ability and epithelial cells facilitate underlying cells of mesenchymal origin, what ultimately will influence wound healing and regeneration.

In general, cleft lip and palate disordered tissue showed weak RYK expression. Halford with colleges report that RYK-deficient mice have a distinctive craniofacial appearance, shortened limbs and postnatal mortality due to feeding and respiratory complications associated with a complete cleft of the secondary palate [7]. Data about about specific RYK expression during development of secondary palate practically are not found. Thereby our results demonstrate that RYK gene is inessential in postnatal pathogenesis.

TGF $\beta-3$ is key regulator in fusion of the palatal seam [14]. It influences synthesis of glycosaminoglycan - hyaluronan. Studies show that hyaluronan is synthesized by both the epithelium and mesenchyme. In normal palate development it has been proposed that the main intrinsic force for elevation is provided by hyaluronan [6]. Interestingly, TGF $\beta-3$ affects expression of PAX9. Sasaki with coworkers report, that in TGF- $\beta 3$ null mice expression of PAX9 was reduced medially on unfused palates [23]. Our results also showed quite pronounced expression of TGF $\beta-3$ in cleft lip and palate disordered tissue, especially in epithelium. Thereby we can suppose that mentioned growth factor probably is delayed, but still tissue remodeling contributing signal. Moreower, recent studies confirm, that TGF $\beta-3$ prevents scarring of buccal mucosa and vocal folds $[19,20]$.

Balance between MMPs and TIMPs is among the critical determinants that control the integrity of the ECM and subsequently affect cell fate. Blavier with colleges report that TIMP-2 is diffusely expressed in the mesenchymal tissue of the palate and very intensely apperas at the site of contact between the palatal shelves [1]. It is immunohistochemically demonstrated that MMP-9 also is expressed during palate development [3]. Our results showed in general slight expression of MMP-8 in epithelium, more pronounced expression MMP-9 
in epithelium and underlying connective tissue and very variable number of TIMP-2 positive structures. Interestingly, tissue analysis showed regularity: tissue samples with more relative number of TIMP-2 positive structures had also more MMP-9 positive structures. Moreover, expression of MMP-9 slightly predominated and was found also in the basal epithelial cells. It is known, that MMP-9 (gelatinase) digests a number of ECM molecules including type IV, $\mathrm{V}$ and XI collagens, laminin, aggrecan and core protein [16]. Thus we suggest that cleft lip and palate affected tissue demonstrate weak, but at the same time positive signal for tissue remodeling possibilities.

Thus we conclude:

1. expression of PAX9 is more characteristic for cleft lip and palate affected tissue and probably facilitates tissue reconstruction due to its mitogenic effect,

2. rich expression of TGF $\beta-3$ in cleft lip and palate disordered tissue may play a role in successful tissue remodelling and scar-free healing,

3. cleft lip and palate disordered tissue are characterizied by more pronounced expression of MMP-9, it slightly predominate expression of TIMP-2, giving evidence to the involvement of this mentioned factors in the postnatal tissue remodeling.

\section{REFERENCES}

1. Blavier L., Lazaryev A., Groffen J., Heisterkamp N., DeClerck Y.A., Kaartinen V. (2001). TGF-beta3-induced palatogenesis requires matrix metalloproteinases. Mol Biol Cell, 12, 1457-1466.

2. Chi N., Epstein J.A. (2002). Getting your Pax straight: Pax proteins in development and disease. Trends in Genetics, 18 (1), 41-47.

3. De Oliveira Demarchi A.C., Zambuzzi W.F., Paiva K.B., da Silva-Valenzuela M., Nunes F.D., de Cássia Sávio Figueira R., Sasahara R.M., Demasi M.A., Winnischofer S.M., Sogayar M.C., Granjeiro J.M. (2010) Development of secondary palate requires strict regulation of ECM remodeling: sequential distribution of RECK, MMP-2, MMP-3, and MMP-9. Cell Tissue Res, 340 (1), 61-69.

4. Doshi R.R., Patil A.S. (2012). A role of genes in craniofacial growth. IIOABJ, 3 (2), 19-36.

5. Dudas M., Li W.Y., Kim J., Yang A., Kaartinen V. (2007). Palatal fusion - Where do the midline cells go? A review on cleft lip palate, a major human birth defect. Acta Histochem, 109, 1-14.

6. Galloway J.L., Jones S.J., Mossey P.A., Ellis I.R. (2013). The control and importance of hyaluronan synthase expression in palatogenesis. Front Physiol, 4, 10. 
7. Halford M.M., Armes J., Buchert M., Meskenaite V., Grail D., Hibbs M.L., Wilks A.F., Farlie P.G., Newgreen D.F., Hovens C.M., Stacker S.A. (2000) Ryk-deficient mice exhibit craniofacial defects associated with perturbed Eph receptor crosstalk. Nature Genetics, 25, 414-418.

8. Hamachi T., Sasaki Y., Hidaka K., Nakata M. (2003). Association between palatal morphogenesis and Pax9 expression pattern in CL/Fr embryos with clefting during palatal development. Arch Oral Biol, 48, 581-587.

9. Heiko P., Neubüser A., Kratochwil K., Balling R. (1998). Pax9-deficient mice lack pharyngeal pouch derivates and teeth and exhibit craniofacial and limb abnormalities. Genes\&Development, 12, 2735-2747.

10. Hilliard S.A., Yu L., Gu S., Zhang Z., Chen Y.P. (2005). Regional regulation of palatal growth and patterning along the anterior-posterior axis in mice. J Anat, 207(5), 655-667.

11. Iseki S. (2011). Disintegration of the medial epithelial seam: is cell death important in palatogenesis? Develop Growth Differ, 53, 259-268.

12. Letra A., Silva R.M., Motta L.G., Blanton S.H., Hecht J.T., Granjeirol J.M., Vieira A.R. (2012). Association of MMP3 and TIMP2 promoter polymorphisms with nonsyndromic oral clefts. Birth Defects Res A Clin Mol Teratol, 94 (7), 540-548.

13. Li Q., Ding J. (2007). Gene expression analysis reveals that formation of the mouse anterior secondary palate involves recruitment of the cells from the posterior side. Int J Dev Biol, 5, 167-172.

14. Meng L., Bian Z., Torensma R., Von den Hoff J.W. (2009). Biological mechanism in palatogenesis and cleft palate. J Dent Res, 88, 22-33.

15. Murray J.C. (2002). Gene/environment causes of cleft lip and/or palate. Clin Genet, 61, 248-256.

16. Nagase H., Visse R., Murphy G. (2006). Structure and function of matrix metalloproteinases and TIMPs. Cardiovasc Res, 69 (3), 562-573.

17. Nakajima A., Ito Y., Asano M., Maeno M., Iwata K., Mitsui N. (2007). Functional role of transforming growth factor- $\beta$ type III receptor during palatal fusion. Dev Dyn, 236, 791-801.

18. Nikopensius T., Kempa I., Ambrozaitytė L., Jagomägi T., Saag M., Matulevičienè A., Utkus A., Krjutškov K., Tammekivi V., Piekuse L., Akota I., Barkane B., Krumina A., Klovins J., Lace B., Kučinskas V., Metspalu A. (2011). Variation in FGF1, FOXE1, and TIMP2 genes is associated with nonsyndromic cleft lip with or without cleft palate. Birth Defects Res A Clin Mol Teratol, 91 (4), 218-225.

19. Ohno S., Hirano S., Kanemaru S., Kitani Y., Kojima T., Ishikawa S., Mizuta M., Tateya I., Nakamura T., Ito J. (2012). Transforming growth factor $\beta 3$ for the prevention of vocal fold scarring. Laryngoscope, 122 (3), 583-589.

20. Ohno S., Hirano S., Kanemaru S., Tateya I., Kitani Y., Kojima T., Nakamura T., Ito J. (2011). Prevention of buccal mucosa scarring with transforming growth factor $\beta 3$. Laryngoscope, 121 (7), 1404-1409. 
21. Okano J., Suzuki S., Shiota K. (2006). Regional heterogeneity in the developing palate: morphological and molecular evidence for normal and abnormal palatogenesis. Congenital Anomalies, 46, 49-54.

22. Pilmane M. (1997). Immunohistochemical and radioimmunohistochemical investigations of lung diffuse neuroendocrine system in humans with different respiratory diseases. Riga: Latvian Medicine Academy, 13.

23. Sasaki Y., O’Kane S., Dixon J., Dixon M.J., Ferguson M.W.J. (2007). Temporal and spatial expression of Pax9 and Sonic hedgehog during development of normal mouse palates and cleft palates in TGF- $\beta 3$ null embryo. Arch Oral Biol, 52, 260-267.

24. Trivier E., Ganesan T.S. (2002). RYK, a catalytically inactive receptor tyrosine kinase, associates with EphB2 and EphB3 but does not interact with AF-6. J Biol Chem, 277 (25), 23037-23043.

25. Watanabe A., Akita S., Tin N.T., Natsume N., Nakano Y., Niikawa N., Uchiyama T., Yoshiura K. (2006). A mutation in RYK is a genetic factor for nonsyndromic cleft lip and palate. Cleft Palate Craniofac J, 43 (3), 310-316.

\section{Address for correspondence:}

Benita Krivicka,

Institute of Anatomy and Anthropology of Riga Stradiņš University,

Dzirciema street 16, Riga, LV-1007, Latvia.

E-mail address: b.krivicka@inbox.lv 